\title{
AUMENTO DO DESEMPENHO ORGANIZACIONAL ATRAVÉS DA MERITOCRACIA
}

Walmir Güntzel ${ }^{1}$

\section{RESUMO}

$\mathrm{Na}$ atualidade, quando a concorrência se faz presente em todos os setores da economia e cresce constantemente, as organizações buscam formas diferentes para aumentarem a sua produtividade e se tornarem cada vez mais competitivas, no ensejo de alcançarem suas metas e objetivos. Consequentemente, buscam gerar maiores lucros nas suas atividades. Uma gestão mais efetiva de pessoas é fator indispensável ao sucesso organizacional, e a prática dos sistemas meritocráticos é uma das diversas ferramentas e instrumentos encontrados nesse tipo de gestão. $O$ uso desses sistemas vem se tornando uma prática cada vez mais presente nas empresas, com a promessa de reter seus melhores empregados, já que o talento humano é um grande diferencial para as empresas. Este artigo tem o objetivo de buscar esclarecer os impactos da implementação da meritocracia no ambiente organizacional, bem como os benefícios atrelados a sua prática, possibilitando a melhoria na qualidade de vida dos empregados e identificando as formas de recompensas que mais se destacam no ambiente empresarial. Hoje em dia, é comum encontrar muitos gestores, dos mais diferentes segmentos e mercados de atuação, que afirmam desenvolver e incentivar em suas organizações práticas que visam a aumentar a produtividade e a qualidade nos processos realizados e a um maior nível por parte de seus empregados. Dentre tais práticas, as que estão ligadas a sistemas de recompensa ou aos sistemas meritocráticos são as mais praticadas.

Palavras-chave: Meritocracia. Talento humano. Benefícios.

\section{ABSTRACT}

In the present, where competition is present in all sectors of the economy, and grows in a constant, organizations seek different ways to increase their productivity and to become

\footnotetext{
${ }^{1}$ Administrador, Mestre pela Universidade de Ciências Empresarias e Sociais da Argentina e coordenador/professor do curso de Administração FAE (Sapucaia do Sul)/RS. Professor das Faculdades Integradas de Taquara (Faccat)/RS, Castelli (Canela)/RS e Faccca (Camaquã)/RS. walmir.admin@gmail.com
} 
more and more competitive, in the opportunity to achieve their goals and objectives and consequently seek to create higher profits in their activities. More effective management of people is an essential factor to organizational success, and the practice of meritocracy system is one of several tools and instruments found in this type of management. The meritocratic system use is becoming a practice increasingly present in companies with the promise of retaining their best employees, since human talent is a big differential for companies. This article has the objective on seek of clarifying the impact of the implementation of meritocracy in organizational environment, as well as the benefits related to its practice, enabling the improvement on employees quality life and identifying forms of rewards that stand out in the business environment. Nowadays it is common to find many managers, from different segments and marketplaces, that claiming to develop and encourage in their organizations practices that aim to increase the productivity and the quality on procedures realized and a higher level by their employees. Among such practices, which are linked to reward systems, or the meritocratic systems, are the most practiced.

Keywords: Meritocracy. Human talent. Benefits.

\section{INTRODUÇÃO}

De que maneira a meritocracia pode influenciar no desempenho dos empregados? Para buscar a resposta a essa questão, recorreu-se ao estudo das obras de autores que tratam justamente dos sistemas meritocráticos nas empresas, tais como: John Rawls, Lívia Barbosa, Max Gehringer e Idalberto Chiavenato e Stephen P. Robbins.

O interessante acerca desse tema é o tom de excepcionalidade e novidade em que ele vem envolto sempre que vem à tona, como se o Brasil fosse um caso especial e a adoção da meritocracia nos colocasse no primeiro mundo. Duas perguntas cabem de imediato. Primeira: será que se justifica o caráter de novidade e modernidade que quase sempre acompanha as discussões sobre o estabelecimento de uma meritocracia nos serviços públicos e privados no Brasil? Segunda: será que cabe o tom de excepcionalidade no caso do Brasil?

A resposta à primeira pergunta é negativa, se considerarmos a evidência histórica, tanto geral como específica. Sistemas meritocráticos não é uma invenção da modernidade e, no Brasil, desde 1824, é possível registrar a presença de um desses sistemas em termos de formulação jurídica. Portanto, se há mais de um século e meio já existia a iniciativa de se estabelecer entre nós um sistema desse tipo, a questão que parece mais relevante é: por que essa forma de hierarquização não consegue se reproduzir e, principalmente, encontrar legitimidade na nossa sociedade, considerando-se que, depois daquela data, foram formulados e postos em prática vários planos que procuravam estabelecer uma meritocracia nos serviços brasileiros?

A resposta à segunda questão também é negativa. Qualquer revisão de bibliografia especializada indicará que a questão da meritocracia e da sua avaliação é polêmica para toda a teoria da administração moderna e envolve uma dimensão política não só no 
Brasil como em outros países também. A partir dessas constatações, cabe perguntar em que medida um novo plano de avaliação de desempenho - que hoje aparece atrelado à reforma do Estado - poderá atingir os resultados almejados?

A questão não é a existência de um sistema de meritocracia nas organizações, mas sim a sua legitimidade na prática. Ou melhor, a transformação desse sistema meritocrático existente no plano formal e no plano do discurso em uma prática meritocrática.

Essa transformação, contudo, não surgirá como uma consequência natural de bons e modernos planos de avaliação de desempenho e produtividade, porque, na realidade, já tivemos vários deles. Não virá nem de avaliadores treinados e preparados para executá-los, nem da vontade política de uma única organização. A questão é muito mais ampla e não será resolvida automaticamente, apenas pela imposição das organizações, nem com a introdução de uma nova metodologia de aferição de desempenho. Deverá ser entendida a raiz da diferença entre a existência de sistemas meritocráticos formais e sua legitimidade prática, o que é desempenho e mérito para os diferentes grupos da sociedade brasileira e como as diferentes percepções destas categorias culturais se relacionam com outros valores centrais na nossa dinâmica social - como lealdade, dedicação e relações pessoais. Além desses, também é necessário entender o que significa, do ponto de vista sociológico, no Brasil, excluir por falta de desempenho e, finalmente, como esses temas se relacionam com fluxos culturais mais amplos, com as teorias da moderna administração de gestão de pessoas e com as mudanças nas relações de trabalho em curso no mundo capitalista. Em suma, não avançaremos muito mais se não buscarmos entender o que realmente está sendo dito nesse debate cultural pelos diferentes grupos que dele participam.

\section{MERITOCRACIA, AVALIAÇÃO DE DESEMPENHO E PRODUTIVIDADE}

Com um foco muito além de manter um bom desempenho organizacional, as empresas precisam buscar formas de estimular um bom desempenho do trabalhador. Uma das formas possíveis para alcançar esse objetivo é a utilização da meritocracia, que visa trazer metas individuais bem definidas para os empregados, que são estimulados pela premiação de acordo com o mérito individual. A pergunta que o presente artigo pretende responder é: a meritocracia melhora o desempenho do empregado?

A partir da avaliação de desempenho dos empregados de uma instituição, podemos identificar as áreas nas quais o treinamento se faz necessário, se os critérios de seleção utilizados são realmente adequados, se estão selecionando as pessoas certas para os lugares certos, que empregados devem ser remanejados para serem melhor aproveitados.

Embora a filosofia da avaliação de desempenho tenha mudado e, na época atual, ela seja concebida como um poderoso instrumento para a orientação e promoção do crescimento pessoal e profissional das pessoas e das empresas, na prática, contudo, ela é uma fonte de atritos, insatisfações e frustrações para aqueles que a concebem e aplicam, bem como para aqueles que são alvo de sua aplicação. Essa constatação é comum não só no Brasil como também em outros países.

Entretanto, o ataque mais famoso de toda a teoria da administração contra a avaliação de desempenho dos assalariados partiu de Edward Deming, guru norte-ameri- 
cano dos programas de qualidade no Japão, que considera esse processo uma das cinco doenças fatais que atingem a administração. Segundo Deming (1992), o sistema anual de avaliação de desempenho dos assalariados é negativo porque é um sistema arbitrário e injusto, que desmoraliza os empregados, alimenta o desempenho imediatista, aniquila o trabalho em equipe, estimula o medo e a mobilidade administrativa, já que as pessoas mal avaliadas tendem a procurar outros empregos.

Outros teóricos, como Juran, Gryna e Bingham (1974) e Robbins (2003), ligados também aos programas de qualidade, afirmam que se 80 a $85 \%$ dos problemas das empresas são de origem sistêmica e não da responsabilidade individual dos empregados, como avaliá-los devidamente? Como será possível discernir, em um mau desempenho, a parcela de culpa do sistema e a da responsabilidade do empregado?

Todavia, paralelamente à visão anterior, encontramos especialistas que vêem na avaliação de desempenho uma necessidade fundamental para qualquer administração moderna. É francamente reconhecido que os sistemas de apuração ou de avaliação do merecimento revelaram-se, no passado, acima de tudo, rudimentares e imperfeitos processos de apreciação e registro de aptidões e hábitos de trabalho. A administração de recursos humanos deve aceitar o desafio da situação e buscar desenvolver instrumentos mais adequados e úteis aos dias de hoje.

Para aqueles que defendem a avaliação de desempenho, a questão se reduz a encontrar o melhor método de avaliação. Nessa perspectiva, toda a discussão sobre o assunto torna-se uma discussão formal, de como fazer, e não uma discussão substantiva, sobre se desempenho e mérito podem e devem ser medidos e avaliados e em que consistem.

Os argumentos a favor da avaliação de desempenho fundamentam-se em dois tipos de causas: uma de natureza pragmática e outra de cunho psicológico. A primeira afirma que vários outros subsistemas da área de recursos humanos - e não só a avaliação de desempenho - ensejam também distorções como o recrutamento, a seleção, a demissão e a movimentação das pessoas no interior da empresa e nem por isso deixam de ser realizados. A razão para isso é muito óbvia: toda e qualquer empresa precisa selecionar, encarreirar e excluir pessoas, pois os quadros de uma empresa não são ilimitados, tampouco a inserção é uma decisão voluntária e unilateral. Portanto, a avaliação, como a seleção de pessoas, é uma exigência lógica do próprio sistema econômico administrativo.

A segunda se baseia em uma visão acerca da constituição da natureza humana, que é bem sintetizada pelas teorias da motivação produzidas nos Estados Unidos por David McClelland, Abraham Maslow, Frederick Herzberg e Victor Vroom. Não cabe resenhá-las aqui uma a uma, mas, de modo geral, essas teorias afirmam que os atos humanos são movidos por ações racionais, motivadas ou impulsionadas por forças interiores, que visam satisfazer alguma necessidade humana básica. Negar reconhecimento e espaço para esses impulsos humanos universais é o caminho mais rápido para o desestímulo, a baixa produtividade e a estagnação, pois tira do homem a vontade de crescer e progredir.

Neste contexto, a avaliação de desempenho e o resultado que dela advém, em termos de mobilidade vertical interna nas empresas, funciona como um instrumento fundamental para a satisfação de algumas necessidades, induzindo as pessoas a tentarem obter resultados melhores com vistas a obterem recompensas maiores. 
Na prática, os dilemas criados pelos sistemas de avaliação de desempenho têm sido, desde o início, resolvidos pela teoria de administração e pelos administradores através da atribuição de culpa aos instrumentos utilizados para a avaliação. Ou os sistemas utilizados são vistos como inadequados, ou os avaliadores são considerados mal preparados.

O objetivo, então, é encontrar um sistema de avaliação ideal e uma metodologia que consiga, de alguma maneira, neutralizar ou controlar a subjetividade do avaliador. O que se observa, então, é uma crítica permanente ao sistema em uso e a proposta de novos planos que terminam sempre tendo o mesmo destino do que o precedeu.

O que é realmente importante para os nossos propósitos é enfatizar que meritocracia e a sua aferição não são uma questão tranquila para a teoria da administração. Portanto, os descompassos existentes entre nós não são fruto de nenhuma incapacidade nativa de implementação.

\subsection{Meritocracia}

Conforme disposto no dicionário da língua portuguesa, o significado de meritocracia é a forma de liderança que se baseia no mérito, nas capacidades e nas realizações alcançadas em detrimento da posição social.

John Rawls (2005), criador da teoria da justiça, em sua tese sobre liberalismo, trata da importância da meritocracia para uma sociedade justa, porém ressalta que é necessário que todos os indivíduos tenham acesso a um igual nível de estrutura educacional, garantindo, assim, que suas aptidões sejam desenvolvidas independentemente da origem social e condição econômica.

Em sua provável primeira aparição a palavra meritocracia foi descrita por Michael Young (1958), como prenúncio de dias futuros nos quais a posição social seria determinada pela capacidade cognitiva somada ao esforço de cada indivíduo. Sua descrição da meritocracia trazia um sentido pejorativo.

Lívia Barbosa (1999, p. 22) traz, em um nível ideológico, a meritocracia como "[...] um conjunto de valores que postula que as posições dos indivíduos na sociedade devem ser consequência do mérito de cada um". A autora também traz a afirmativa que a meritocracia é um sistema essencial às sociedades democráticas modernas e igualitárias, dando por referência o art. 6 da Declaração dos Direitos do Homem e do Cidadão Francês. Segundo essa declaração, todos são iguais perante a lei, portanto, estão igualmente aptos a ocupar posições, cargos e empregos de acordo com sua capacidade e sem qualquer outra distinção que não sejam suas virtudes e talentos. A constituição francesa de 1793, em seu art. 5, também estabelece que todos os cidadãos estão capacitados aos cargos públicos e que uma cidadania livre não pode demonstrar preferências pelos seus servidores, a não ser aquelas baseadas no caráter e no talento.

Ainda defendendo a meritocracia como um sistema essencial às sociedades democráticas modernas, explanando especificamente sobre a "meritocracia à brasileira", Lívia Barbosa (1999, p. 49) cita a constituição brasileira de 25 de março de 1824, no art. 179, item XIV: “todo cidadão pode ser admitido aos cargos públicos civis, políticos ou militares, sem outra diferença que não seja por seus talentos ou virtudes". 
Trazendo um comparativo entre democracia e meritocracia, Afirma Max Gehringer (2007, p. 148):

\begin{abstract}
Ao contrário da democracia, um conceito político que significa 'governar para todos', meritocracia é um conceito político que significa 'governar para aqueles que merecem'. Numa meritocracia, todos os funcionários têm objetivos individuais. E os objetivos de cada funcionário são claros, são mensuráveis, são pesados, são difíceis de atingir, e estão diretamente ligados ao crescimento da empresa. [...] Hoje, qualquer empresa sabe quanto um funcionário custa. Mas só aquelas que adotam a meritocracia sabem quanto um funcionário realmente vale.
\end{abstract}

\title{
2.2 Desempenho
}

Chiavenato (2009, p. 242) sintetiza o desempenho como uma relação de custo benefício, porém relata sua dependência com relação a algumas variáveis que a condicionam:

\begin{abstract}
O desempenho humano na organização é extremamente contingencial. Varia de pessoa para pessoa e de situação para situação, pois depende de inúmeros fatores condicionantes que influenciam poderosamente. [...] Uma apreciação da relação custo/benefício que cada pessoa faz para poder avaliar até quanto vale a pena fazer um determinado esforço. Por sua vez, o esforço individual depende das competências individuais da pessoa e da sua percepção do papel a ser desempenhado. Assim, o desempenho é função de todas essas variáveis que condicionem fortemente.
\end{abstract}

É fator de grande importância que o desempenho seja gerenciado e mensurado. Deming (1992, p. 113) destaca a grande importância do gerenciamento para o sucesso de qualquer processo: "Não se gerencia o que não se mede, não se mede o que não se define, não se define o que não se entende, não há sucesso no que não se gerencia".

\subsection{Igualdade e desempenho}

À primeira vista, pode parecer absolutamente estranho relacionar a ideia de igualdade à questão da avaliação de desempenho. Igualdade parece ser um valor político mais associado a questões, opiniões e atitudes relativas a eleições, candidatos, governo e ideologias. Na realidade, a ideia de igualdade é muito mais do que um tema político: ela é um valor estrutural nas sociedades modernas, na medida em que se configura como um dos atributos centrais do personagem social característico dessas sociedades - o indivíduo.

Mas, por que igualdade se relaciona com desempenho? Porque, de acordo com a ideologia das sociedades modernas, todos os indivíduos nascem livres e iguais. Além de sujeitos empíricos, eles também são sujeitos morais. Isso significa que nenhum atributo social do tipo ascendência, riqueza, status, relações pessoais, etc. pode ser levado em conta no tratamento que a sociedade dispensa aos seus membros. Eles não definem o indivíduo. O que define o indivíduo é uma suposta semelhança moral dada pela existência de uma dimensão natural/física idêntica entre todos os seres humanos. Essa seme- 
Ihança de forma é tomada como base de um sistema de direitos ao qual todos devem ter acesso igual. Nesse contexto, o único elemento a diferenciar uma pessoa da outra são as suas características idiossincráticas, ou seja, tanto os seus talentos naturais como a sua disposição interior para realizar o que os norte-americanos de achievement. A única hierarquia ideologicamente possível é aquela construída a partir da avaliação dos diferentes desempenhos individuais.

Contudo, para que o desempenho dos indivíduos tenha legitimidade social, ele deve estar inserido em um contexto juridicamente igualitário, no qual a igualdade funcione, mesmo que simbolicamente, como uma moldura para os acontecimentos e proporcione as condições para que as pessoas sejam avaliadas exclusivamente pelas suas realizações. Ou seja, nenhum outro critério como, por exemplo, poder econômico, status, relações familiares e pessoais pode influenciar nessa avaliação. É por isso que desempenho e igualdade estão intimamente associados. Essa última fornece as condições necessárias e suficientes para a sua legitimidade.

As variações começam a surgir quando saímos desse nível geral da ideologia e passamos à sua implementação prática em universos sociais distintos. Então, é possível observar que os conceitos anteriores - igualdade, desempenho e mérito -, embora continuem na base da organização social e administrativa das sociedades complexas, possuem conteúdos sociais distintos, bem como as condições sociais consideradas legítimas para a avaliação das produções individuais.

As implicações dessas variações são básicas para o nosso objetivo, pois, se compararmos as concepções sobre igualdade e desempenho desenvolvidos no Brasil e nos Estados Unidos, podemos entender porque, embora possuamos sistemas meritocráticos, esses não possuam legitimidade na nossa prática social. Poderemos constatar, sem muita dificuldade, que o discurso oficial da sociedade norte-americana sobre desempenho e igualdade assemelha-se ao que alguns grupos da sociedade brasileira, particularmente as elites políticas e econômicas e os setores mais individualistas e intelectualizados da população, pensam que deva ser desempenho e igualdade. Esse discurso, contudo, contrasta bastante com a prática social de todos os segmentos da população brasileira que, no momento de aplicar no seu contexto e para si e o seu grupo de princípios, atribui ao que se entende por desempenho um sentido bastante distinto do norte-americano.

\section{DESENVOLVIMENTO}

Frederick Taylor (apud CHIAVENATO, 2003, p. 72) destaca a importância da valorização do trabalho dos funcionários quando observa que ao igualar os salários dos funcionários mais produtivos com o dos menos produtivos é "desmotivante e contraproducente para os primeiros".

Gehringer (2007, p. 115) menciona a meritocracia no contexto empresarial, defendendo a tese do crescimento da utilização desse tipo de estratégia no contexto atual e futuro, devido ao novo perfil de menor burocracia e maior flexibilidade das empresas, ele relata que: 
Para a empresa, é muito melhor que a remuneração seja proporcional ao resultado. Esse sistema chamado de meritocracia é baseado em metas e objetivos individuais e dá oportunidade aos bons de ganhar mais que os acomodados. Mas, principalmente, ajuda a empresa a equilibrar as contas de modo mais eficiente. Por isso o futuro dos salários será mesmo a remuneração variável e mais uma pequena parcela fixa, como determina a lei. Um pouco porque esse é um sistema justo.

Peter Drucker (1997) ressalta a grande necessidade do bom desempenho não apenas nos grandes escalões da empresa, advertindo que é intrínseca a necessidade da boa administração do desempenho do trabalho e do trabalhador para obter êxito, pois, mesmo com uma excelente administração do presidente da empresa em relação ao seu negócio, um mau desempenho nos demais níveis da empresa resultam em "destruição de capital, mesmo a curto prazo" (p. 39).

A meritocracia visa estimular esse bom desempenho. Para isso, é preciso que o empregado saiba claramente sua importância para o desenvolvimento das tarefas da organização. A partir do momento em que o empregado entende seu papel dentro do ciclo organizacional e tem benefícios quando se torna mais produtivo, automaticamente ele se motiva e passa a ter pensamento de colaborador.

O sistema de mérito está entre os principais fatores que permite a companhia avançar em um mercado altamente competitivo, trazendo a ideia de que a meritocracia vai além do bônus e garante reconhecimento e ascensão profissional acima da média do mercado. Também significa transparência, cooperação interna e ética na obtenção de resultados, além da atitude de donos do negócio. São esses os fatores que entendemos como essenciais na atitude de nossos empregados.

Chiavenato (2009) defende a tese de que o simples fato de utilizar sistemas meritocráticos não é garantia de sucesso nem trará os resultados esperados para organizações empregados. É necessário que tal prática seja implementada de maneira transparente, justa e coerente, para que todos os envolvidos se sintam parte importante do processo e se empenhem na busca das metas propostas, pois terão a ciência de que serão beneficiados com esta prática.

A meritocracia também resulta em modificação na qualidade de vida dos empregados da organização. Essa melhora de qualidade de vida é devido ao salário, pois os empregados são motivados e absorvem com certa tranquilidade a pressão natural que sofrem dentro da empresa pela busca de metas. Isso se dá quando a recompensa é com justiça e transparência. Esse conceito de justiça é fundamental para transformar a meritocracia em uma ferramenta de gestão poderosa quando se trata de produtividade. Nesse caso, políticas para o cultivo da justiça é uma boa opção para melhorar o desempenho, motivar e reter talentos, já que, nesse sistema de recompensas, cada empregado é responsável pelo valor de sua remuneração e pelo desenvolvimento de sua carreira, possuindo motivação e estímulo para alcançar seus objetivos e metas.

\section{CONCLUSÃO}

Este artigo teve a proposta de identificar se a gestão por mérito propicia aumento no desempenho do empregado a partir da análise da literatura de importantes autores e 
experiências do uso da meritocracia por profissionais que atuam no mercado, inclusive do autor.

Após análise de obras de diversos autores, fica evidente a importância do reconhecimento e valorização de forma justa e adequada a quem realmente possui mérito. Enaltecer e disseminar essas boas práticas aumenta consideravelmente o desempenho do empregado e diretamente o seu comprometimento com as metas propostas, fazendo com que este se sinta parte importante da empresa, verdadeiro colaborador, aumentando o seu desempenho pessoal dentro da empresa, assim como os resultados desta.

Em vista dos argumentos apresentados, torna-se evidente que o desejo das empresas que se utilizam da meritocracia é obter e reter consigo equipes de alto nível de comprometimento e de técnica, pessoas que se destaquem e visem ao crescimento. Foram apresentados diversos resultados positivos de sua implementação, demonstrando a grande incidência da sua utilização em empresas importantes no mercado e sua contribuição para os desempenhos de excelência alcançados.

A questão básica para o entendimento e a busca pela meritocracia para o alto desempenho organizacional é obter avaliadores preparados, capacitados, principalmente do peso das relações pessoais no resultado das avaliações de desempenho individual, oriundos de mecanismos que exigem as suas respectivas contextualizações e explicitações.

Com base nas opiniões de especialistas, empresários e profissionais de Recursos Humanos, podemos concluir que a meritocracia é um modelo de gestão que proporciona crescimento, pois fomenta profissionais ávidos em aprender e buscar novas técnicas de inovação, envolvidos no crescimento das organizações, já que são estimulados a isso a partir de recompensas e do reconhecimento justo pelo que fazem.

\section{REFERÊNCIAS}

BARBOSA, Lívia. Igualdade e meritocracia. Rio de Janeiro: FGV, 1999.

CHIAVENATO, Idalberto. Desempenho humano nas empresas. São Paulo: Manole, 2009. Introdução à teoria geral da administração das organizações. 7 ed. Rio de Janeiro: Elsevier, 2003.

DEMING, W. Edward. Qualidade: A revolução da Administração. São Paulo: Saraiva, 1992.

DRUCKER, Peter. Fator humano e desempenho. São Paulo: Pioneira, 1997.

GEHRINGER, Max. Pergunte ao Max Gehringer. Rio de Janeiro: Globo, 2007.

JURAN, Joseph M.; GRYNA, Frank M.; BINGHAM, Richard S. Quality Control Handbook. McGraw-Hill Book Company, 1974.

RAWLS, John. Political liberalism. New York: Columbia University, 2005.

ROBBINS, Stephen P. Verdade sobre gerenciar pessoas. Rio de Janeiro: Prentice Hall do Brasil, 2003.

YOUNG, Michael. The rise of the meritocracy. Piscataway: Transaction Pub, 1958. 